\title{
Let's keep metaphysics out of medical ethics: a critique of Poplawski and Gillett
}

\author{
Frank J Leavitt Ben-Gurion University of the Negev, Beer Sheva, Israel
}

\section{Author's abstract}

I argue that the concept of 'longitudinal form', which

Poplawski and Gillett have introduced into ethical

discussions about embryos and gametes, involves too many metaphysical subtleties to be a useful aid to making moral decisions. I conclude by suggesting a criterion for relevance in medical ethics.

The very features which make a concept interesting philosophically may lessen its potential for clarifying difficult moral questions. Poplawski and Gillett (1) have introduced the concept of 'longitudinal form' in order to make what they consider an improvement in the 'standard potentiality argument' for ascribing moral value to embryos. They call the concept of longitudinal form 'Aristotelian', probably because of Aristotle's stress on the moral importance of 'a complete life' (2). But the concept probably owes no less to Spinoza's view of things sub specie aeternitatis (3) and to Quine's 'tenseless' treatment of quantification (4). While the concept of longitudinal form embodies a respectable doctrine in philosophical logic and in metaphysics, it raises so many subtle philosophical questions that I doubt whether it can be of value for medical ethics. We want our discussions of embryos, for example, to help pregnant women to decide whether or not to have abortions, to help in vitro fertilisation (IVF) workers to decide what to do with 'excess' embryos, to help research people decide whether or not to get involved in 'creating' embryos. I doubt whether the subtle questions which the concept of longitudinal form raises can do any more than confuse the people whom medical ethics ought to be helping.

Through the concept of longitudinal form we see a human being as extended not only in space but also in time. The embryo, the morally competent adult, and the aged man breathing his last gasp on his death-bed are all three 'stages' of one 'continuum' (5).

Poplawski and Gillett point out that during certain stages of this continuum the individual is able to

\section{Key words}

Embryos; gametes; longitudinal form; metaphysics; moral decision-making. 'participate in moral interactions' (5). But since these mature stages are part of the entire temporally extended continuum '... if we can justify a moral value for that individual at one point in time, that moral value ought to be conferred on the total form throughout its temporal existence' (6). An embryo, in particular, derives its moral worth from the fact that it is a necessary condition for the existence of the later stages (5) including the stage of full moral interaction with others.

I shall now discuss some specific difficulties which arise from the concept of longitudinal form. The first three are problems which Poplawski and Gillett find in the 'standard potentiality argument'. I shall argue that the 'longitudinal form' approach also fails to solve these problems.

I) Poplawski and Gillett argue: '... it makes little sense to give an embryo rights that it may have at a later stage unless its potential is an inherent property which confers those rights. Surely we should form attitudes to things on the basis of what they are rather than what they might be' (7)?

But the longitudinal view does not solve this problem. When we have the morally-interacting individual before us and we think backwards in time to the embryo stage, then we may say that the embryo and the more mature stages are temporal parts of the same human being. But when we have only the embryo before us we have no way of knowing whether or not it will become a more mature individual, ie whether or not it is a stage of the same temporally extended organism as is a morally interacting individual. So Poplawski's and Gillett's position, which ascribes moral worth to the embryo in virtue of its being a stage of the same organism as is the morally interacting individual, has no way of ascribing worth to a presently existing embryo 'on the basis of what it is', but can only ascribe this worth - just like the standard potentiality view - on the basis of 'what it might be'.

II) Poplawski and Gillett's second argument against the standard potentiality view is as follows: '... there is the distinct possibility that any given embryo will never reach the stage of having those rights. But many embryos which spontaneously abort are no different from ones that will reach the potential later stage. Why should they have different properties' (7)? 
But for reasons similar to those we saw under I), above, the longitudinal view gives us no practical way to distinguish an embryo which will spontaneously abort from one which will reach a later stage. When the early embryo is before us and its future is unknown the longitudinal view is no more useful for purposes of moral decision-making than is the potentiality view. For we have no way to know whether or not this embryo has a later stage at all.

III) Poplawski and Gillett's third agument against the standard potentiality view is as follows: '... just how far back ought these rights to be extended: should sperm and ova be included? (If so we ban contraception' (7).)

Let us adopt the longitudinal view, and let us assume that there stands before us a fully mature, morallyinteracting individual. Let us imagine ourselves following him backwards in time as if a film were running in reverse. We arrive at the blastocyst stage. Then we suddenly see it split in two. There is an as-yet unfertilised ovum and a sperm which is hurrying backwards towards the father: why should this pair of gametes not be counted as part of the same spatiotemporally extended organism as is the mature morally-interacting individual? The only relevant difference I can see between the fertilised egg, on the one hand, and the pair of gametes on the other, is that the former is a spatial unity while the latter is in two places at one time. But why should there be anything strange about the idea of one organism being scattered in space? Consider a man who loses a hand in an accident. $\mathrm{He}$ is in hospital while a driver is sent to retrieve the hand to be re-attached. Here one organism is in two places at once. I see no difference with respect to the pair of gametes. In fact, Poplawski and Gillett's longitudinal view seems to make it much easier, and less strange, to regard the pair of gametes as a stage of a spatio-temporally extended organism, than it seemed before they introduced the longitudinal view into discussions of embryos and gametes. For that reason their claim, with respect to a pair of gametes which will, in future, form a person, that 'their separate existences do not constitute part of the development of a human being' (8) seems to me gratuitous.

It has been objected to me that a severed hand is neither organically nor functionally a part of its owner. Until such time as it is rejoined by surgery it cannot even be called a hand except by 'courtesy title'. Similarly, a pair of gametes are not part of ongoing life.

This objection may well be correct according to traditional linguistic usage. Because according to traditional ways of using such terms as 'hand' and 'part of an organism' it may seem strange to say that a severed hand is really the hand of a man from whom it is severed, because it is customary to assume that nothing is a part of an organism unless it forms a spatial unity with it. But linguistic usage can change with developments in science and technology and with the introduction of new philosophical ways of conceiving things. The view which Sir Arthur Eddington went some way towards popularising, according to which we are all collections of tiny discrete particles buzzing about in empty space, has made it easier for us to think of an organism as something which might be scattered in space. Similarly, a person who has come to regard surgical techniques for re-joining severed organs as routine may find no difficulty in referring to a severed hand as a part of a man. And if such a person has also grown accustomed to a longitudinal view of life he may well feel no uneasiness at all in referring to a pair of spatially separate gametes as parts of one ongoing life.

Lest I be misunderstood I stress that I am not, in this essay, taking a stand for or against the morality of contraception. I have merely tried to demonstrate that the longitudinal view of human beings sheds no light on the issue.

In addition to the fact that the longitudinal view does not solve the difficulties which Poplawski and Gillett find in the standard potentiality approach, the longitudinal view gives us no clear way out of further complications.

IV) The only basis which Poplawski and Gillett have given us for ascribing moral worth to an embryo is that it is an early stage of a temporally extended organism which will 'participate in moral interactions' (5) at later stages. Now although there is much disagreement about the conditions under which abortions are moral or immoral, most of us agree, 1 think, that there are at least some conditions undef which abortion is immoral. But if we abort an embryo then it immediately fails to be a stage of a temporally extended organism whose later stages participate in moral interactions. So Poplawski and Gillett have no means to ascribe it moral worth. In fact, as a little thought shows, it follows from their view that the only immoral abortions are the unsuccessful ones, for they are the attempts to destroy early stages of organisms whose later stages participate in moral interactions.

I hasten to add that it is not clear to me that the above argument tells any more against Poplawski and Gillett's longitudinal view than it does against standard views which ascribe moral worth to embryos on the basis of their 'potentiality' to develop into full human beings. Given the fact that vast numbers of embryos spontaneously abort or fail to develop fully for any of many reasons, there is no way to know, with respect to a given embryo which happens to be under consideration, whether or not it really does have a 'potential' to develop into a full human being. It might come to an early end through natural causes even if we don't abort it. So in the case of an embryo which we $d o$ abort there can be no empirical basis for the assertion that this embryo had a potential to develop into a full human being. So the standard potentiality view can give us no empirical basis for asserting with respect to a successful abortion that it was immoral. It follows that the standard potentiality view and the longitudinal view are equivalent in the sense that given any set of empirical data, neither one view nor the other requires us to act any differently in the face of that data. So the 
distinction between the two views is 'metaphysical' in the sense that the distinction is morally irrelevant: neither view requires us to act any differently from what the other view requires.

I'll return to this matter of relevancy towards the end of this essay.

V) According to Poplawski and Gillett's approach the important stages of the temporally extended organism are those stages at which it participates in moral interactions with others. This mature stage is what confers moral worth on the other stages. And as they explicitly state, the embryo gets its moral worth from the fact that its existence is a necessary condition for the existence of the morally mature stage. For as they say: 'Note that this view may confer some moral worth on the embryo even at fertilisation. If the initial stage in the human process does not occur none of the later stages can be reached and therefore the first stage is an essential component of the complex whole in the same way that the laying of foundations is the essential first stage of building a house' (5). (Italics mine)

But consider now a very late stage of a human organism: an elderly man breathing his last gasp on his death-bed. He is incapable of participating in moral interaction. But he surely has some moral worth. Since, however, his existence is not a necessary condition for the existence of a stage which is capable of moral interaction, the reason which Poplawski and Gillett explicitly give us for assigning moral worth to an embryo gives us no cause to ascribe moral worth to this dying elderly man. Poplawski and Gillett say that there is 'no difference' between the moral value of a sevenyear-old and a 70-year-old (9). But they give no clear explanation of how their longitudinal view is supposed to provide any reason at all for valuing many aged persons. For while the seven-year-old stage is a necessary condition for the existence of morally more mature stages, a dying aged person who has passed the stages of moral interaction with others is not a necessary condition for the existence of other stages.

VI) According to the longitudinal view, my present stage in life and my future stages are parts of one tenselessly existing organism. So my future actions are part of what I am, and I have no free choice with respect to my future actions. But the philosophical problem of free will is not one of the questions with which someone who has to make a hard choice in medical ethics should have to trouble himself. And since the longitudinal view engenders more philosophical puzzles than it clarifies moral issues, I wish to suggest that in spite of its great interest as a subject for metaphysical speculation, it has little to contribute to medical ethics.

To prevent misunderstanding I want to emphasise that in calling the longitudinal view 'metaphysical' I only intend to stress that it, as I think I have demonstrated, has no import with respect to practical, moral decision-making and that it introduces unnecessary subtleties into medical ethics. Not only do I have no objections to metaphysics as an independent field of enquiry, I happen, as a philosopher, to spend a good deal of my time trying to practise it.

Nor do I deny that the discipline of metaphysics may have some useful concepts to contribute to medical ethics. I have only argued that the concept of longitudinal form is not one of them.

Among philosophers who are dealing with medical ethics there is no lack of painful awareness of the fact that many of our speculations fail to contribute anything towards helping people make practical moral decisions. I would like to make a suggestion towards developing a Criterion of Relevance for concepts in medical ethics similar to the logical positivists's criterion of meaning for empirical statements. One way of stating the positivists's Verification Principle is to say that if there is no difference between the conditions of verification for two propositions then there is no difference in their meaning. According to the Criterion of Relevance which I want to suggest, a philosophical doctrine is relevant for medical ethics if and only if someone who holds it ought to act differently in particular practical moral situations, from someone who holds a competing doctrine. Since, as we have seen, the longitudinal view of embryos requires one to act no differently from one who holds the standard potentiality view, I call its introduction into medical ethics irrelevant and metaphysical.

My remarks about philosophical metaphysics, moreover, do not apply to religion. While philosophical metaphysical speculations may often be like idle wheels which make no difference to our moral decisions, religious attitudes certainly do make a difference. But an exploration of that point would take us far beyond the purposes of this note.

The Criterion of Relevance which I have roughly sketched in this essay is not entirely new but is based in part upon the practice of the rabbis of the Talmud who would often interrupt an abstract dispute with the question, in Aramaic: mai nafka mina?, meaning 'what comes out of it?' The idea was that if a dispute makes no difference for how we ought to act in practice then the dispute is merely theoretical and practically irrelevant. I have tried to apply this approach to medical ethics by roughly sketching a criterion for distinguishing what is merely metaphysical from what is morally relevant. But I have only been able to make a rough suggestion of how such a criterion ought to be formulated and I hope that further discussion will result in a more precise formulation of the criterion.

Frank $\mathcal{F}$ Leavitt, PhD, is a Lecturer in the Department of Philosophy, and Tutor in the Lord Immanuel Fakobovits Center for Jewish Medical Ethics, Faculty of Health Sciences, Ben-Gurion University of the Negev.

\section{Acknowledgement}

I thank this journal's editor and referees for helpful suggestions.

\section{References}

(1) Poplawski N, Gillett G. Ethics and embryos. Fournal of 
medical ethics $1991 ; 17: 62-69$.

(2) Aristotle. Nicomachean ethics, I7; 1098a: 18ff.

(3) Spinoza B de. Ethics. v,23, scholium.

(4) Quine W V. Methods of logic. London and Henley: Routledge and Kegan Paul, 1974, 1978: 165ff.
(5) See reference (1): 63 .

(6) See reference (1): 64 .

(7) See reference (1): 62 .

(8) See reference (1): 67. (Italics in text)

(9) See reference (1): 66.

\section{News and Notes}

\section{International Association of Bioethics formed}

More than 300 delegates created the International Association of Bioethics at its inaugural meeting earlier this year. The brain-child of Peter Singer and Helga Kuhse of Monash University, Melbourne, Australia and Dan Wikler of the University of Wisconsin at Madison, Wisconsin, USA, the new association brings together members from various academic disciplines from some 34 countries who share an interest in bioethics. The association is committed to free, open and reasoned discussion of bioethical issues and will hold an international conference every two or three years, varying its location. Its next conference is to be in Buenos Aires, Argentina.

Three of the first tasks undertaken by the new association were: to adopt a constitution (one of the features of which is a highly elaborate proportional representation system for voting); to establish networks of members interested in specific fields of bioethical inquiry, and to elect a board of directors. The 21-strong board has members from 17 different countries and was elected from a field of over 40 candidates. The members of the board are predominantly philosophers but also include doctors, lawyers, theologians and an historian.

Board members are: Peter Singer, Australia (president); Helga Kuhse, Australia; Segun Gbadegesian, Nigeria; Raanan Gillon, United Kingdom; Ms Kusum, India; Gamal Serour, Egypt (treasurer); Daniel Wikler, USA (vicepresident); Alastair Campbell, New Zealand; Bartha Knoppers, Canada; Maurizzio Mori, Italy; Ruth Chadwick, United Kingdom (secretary); Hernan Fuenzalida, Chile; Rahito Kimura, Japan; Juan Carlos Tealdi, Argentina (1994 international congress organiser); John Harris, United Kingdom; Bela Blasszauer, Hungary; Ren-Zon Qiu, China; Diego Gracia, Spain; Nalaka Mandis, Sri Lanka; Maurice de Wachter, the Netherlands; Alexander Capron, USA.

Inquiries about the new association, including inquiries about the networks, should be sent to its executive officer, Kay Boyle, Centre for Human Bioethics, Monash University, Clayton, Victoria 3168, Australia. 